\title{
Using a patient-generated mental-health measure 'PSYCHLOPS' to explore problems in patients with coronary heart disease
}

\begin{abstract}
Background

Patients with coronary heart disease (CHD) who are depressed have an increased risk of further cardiac events and higher mortality.
\end{abstract}

\section{Aim}

To use a patient generated instrument (PSYCHLOPS) to define categories of concerns in patients with $\mathrm{CHD}$. To define the psychometric characteristics of patients in each category.

\section{Design and setting}

Cross-sectional study set in general practices in south London.

\section{Method}

Of 3325 patients on the $\mathrm{CHD}$ registers in 15 general practices, 655 completed six baseline psychometric and functional instruments: PSYCHLOPS, HADS-Depression, HADS-Anxiety, Clinical Interview Schedule - Revised, SF12Mental and SF12-Physical. Content analysis was used to categorise patients based on their main problem, as elicited by PSYCHLOPS.

Mean psychometric scores were adjusted for confounding by age, sex, deprivation and ethnicity and calculated for each response category.

\section{Results}

Response categories were: physical problems, both non-cardiac (23.2\%) and cardiac (6.0\%);

social problems: relationship/family (18.2\%), money (7.5\%), work (3.1\%); functional (9.8\%); psychological (6.9\%); miscellaneous (7.3\%); no problem' (18.2\%). The highest psychological distress scores were found in 'physical, cardiac and 'psychological' categories. The 'no problem' category had significantly lower psychological distress and higher functional capacity than other categories.

\section{Conclusions}

PSYCHLOPS enabled the identification of subtypes of CHD patients, based on a classification of self-reported problems. A high proportion of $\mathrm{CHD}$ patients report social problems. Psychological distress was highest in those reporting cardiac or psychological symptoms. Services should be aligned to the reported needs of patients.

\section{Keywords}

primary care: coronary heart disease; functional capacity measures; mental health outcome measures; patient-generated outcome measures.

\section{INTRODUCTION}

Major depression is common in patients with coronary heart disease (CHD); estimates of prevalence range from $15 \%$ to $23 \%$, which contrasts with a reported prevalence of $4.6 \%$ in the general population. ${ }^{1-3}$ When the diagnosis of depression is extended to include minor depression, some studies have found that up to $50 \%$ of patients with CHD experience it. ${ }^{4}$ Patients with CHD who experience depression have an increased risk of further cardiac events, higher mortality rate, ${ }^{1}$ increased service use, and increased perceived severity of symptoms. ${ }^{1.5}$

Depression is a powerful predictor of quality of life in patients with CHD. In one study, depression was the most important predictor of quality of life 1 year after an acute myocardial infarction (MI); more important than demographic and social variables or disease severity. ${ }^{6}$ In another large study of patients with CHD, depression again emerged as the strongest predictor of quality of life, whereas measures of cardiac function (such as cardiac ejection fraction on echocardiography or ischaemia severity on stress echocardiographyl were not significant predictors.

Although research evidence has demonstrated the importance of depression in patients with $\mathrm{CHD}$, there have been few

R Lawton, BSc, research assistant; A Tylee, MD, FRCGP, MRCPsych, professor of primary care mental health, Institute of Psychiatry, King's College London, London. PT Seed, MSc, CStat, senior lecturer in medical statistics, Division of Women's Health, King's College London School of Medicine, London. M Kordowicz, MSc, PhD student; P Schofield, $\mathrm{PhD}$, research fellow; M Ashworth, DM, FRCGP, MRCP, clinical senior lecturer, Department of Primary Care Public Health Sciences, King's College London School of Medicine, London.

\section{Address for correspondence}

Mark Ashworth, Department of Primary Care and studies to determine the main concerns of such patients and how this might relate to their psychometric profiles. Moreover. in-depth qualitative studies tend to involve relatively small-scale samples.

One UK interview study followed the return home of 31 patients after hospital admission for an $\mathrm{Ml}$ and identified a variety of health-related problems that concerned them and had affected their quality of life. Foremost among these were continuing physical symptoms, especially breathlessness, anxiety, and insecurityabout the future, and feelings of overprotection by relatives. ${ }^{8}$ Based on a Swedish survey of 10 patients interviewed 6 weeks after their $\mathrm{MI}$, the most prominent difficulties related to stress management, making lifestyle changes, and to family stress, particularly perceived overprotectiveness.? In a further UK survey of 30 patients with CHD and depression, a strong link was established between depression and reduced functional capacity lespecially loss of the 'breadwinner' role); links were also identified with multimorbidity and problems of a social nature such as loneliness and relationship concerns. ${ }^{10}$

Another means of obtaining qualitative data that are more applicable to larger groups is to use a validated patientgenerated instrument (PGI); these
Public Health Sciences, King's College London School of Medicine, Capital House, 42 Weston Street, London SE1 3QD.

E-mail: mark.ashworthakcl.ac.uk

Submitted: 10 October 2013; Editor's response: 11 November 2013; final acceptance: 17 January 2014.

\section{CBritish Journal of General Practice}

This is the full-length article (published online 27 May 2014) of an abridged version published in print. Cite this article as: $\mathbf{B r} \mathbf{J}$ Gen Pract 2014; DOI: 10.3399/bjgp14X680137. 


\section{How this fits in}

Previous studies using standardised psychological instruments have demonstrated high rates of psychological morbidity in patients with coronary heart disease (CHD). This is the first large-scale survey of patients with $\mathrm{CHD}$ that has been conducted using a patient-generated mental-health outcome measure 'PSYCHLOPS'. This instrument identified main problems experienced by patients, which could be categorised as physical, psychological and social in nature. Patients with continuing cardiac symptoms had notably high psychological distress scores. In spite of their CHD diagnosis, almost one-fifth of patients reported no problems, and had few psychological symptoms and good functional capacity. Commonly used standardised instruments may fail to capture issues of concern to patients with a history of cardiac problems.

instruments are increasingly used to obtain the patient's perspective and to define outcomes that are of importance to them. One form of PGI, Patient Reported Outcome Measures (PROMS), is currently used in a national survey of certain postoperative patients in the UK; 137000 PROMS were returned in the year 2011-2012. ${ }^{11}$ However, these have not yet been validated for mental-health outcomes; ${ }^{12}$ the only PGI that has been validated for use in primary care mental health and can be selfadministered is Psychological Outcome Profiles (PSYCHLOPS). ${ }^{13,14}$

Given the importance of psychological issues in patients with CHD, the study wanted to determine the issues of concern in a large cohort of such patients, as well as the relationship between these concerns and other psychometric characteristics. This study was part of UPBEAT-UK, a larger programme of research into the relationship between $\mathrm{CHD}$ and depression in primary care, and the evaluation of an intervention. ${ }^{15}$ Based on previous qualitative research findings, the study hypothesised that patients with $\mathrm{CHD}$ with continuing cardiac symptoms may differ in their psychometric characteristics when compared with patients reporting other problems. 8,10

This study aimed to use PSYCHLOPS in a primary care cohort of patients with $\mathrm{CHD}$ in order to define categories of patient concern. The psychometric characteristics of each of these categories of concern were then to be defined.

\section{METHOD}

\section{Recruitment and sampling}

The cohort of patients recruited for the UPBEAT-UK study were surveyed..$^{15}$ A total of 15 general practices in south London were recruited to the study with a registered population of 150973 people. Of these, $3325(2.2 \%)$ were on the CHD register, about half of whom had experienced an $\mathrm{Ml}$; the remainder had been diagnosed with ischaemic heart disease, usually on the basis of angina. Patients were excluded from the study if they:

- were non-English speaking;

- had psychotic symptoms;

- were <18-years-old;

- were temporarily registered with the practice; or

- were hospitalised.

Following a postal invitation to participate in the study, 1001 people gave consent to be contacted by the researchers. A total of 803 patients with $\mathrm{CHD}$ consented to the study and completed an interview, together with a series of baseline questionnaires. The analysis was confined to baseline data, although the wider study lasted for 4 years and involved completion of psychometric assessments at 6-monthly intervals. ${ }^{15}$

\section{Psychometric assessments}

PSYCHLOPS was used to produce a categorisation of patients with CHD based on their responses to free-text questions in the questionnaire. The tool consists of four questions, three of which elicit free-text responses. Of these three questions, two are regarding the problems affecting the patient (the first asks about the problem that 'troubles you most'; the second asks about another problem that troubles you') and one deals with the functional impairment resulting from these problems. PSYCHLOPS, therefore, elicits qualitative data encompassing two broad psychometric domains:

- problems; and

- function.

The fourth question is a wellbeing scale. Quantitative data derived from PSYCHLOPS Iscores for each free-text problem and for the wellbeing question) were not used for this study as the overall score is primarily used to determine change over time.

One of the primary objectives of the UPBEAT-UK programme was to explore the 


\section{Table 1. Participants' sociodemographic characteristics $(n=655)$}

\begin{tabular}{|c|c|}
\hline Characteristic & $n(\%)$ \\
\hline Age, years & $70.6(10.9)^{a}$ \\
\hline$<60$ & $99(15.1)$ \\
\hline $60-69$ & $190(29.0)$ \\
\hline $70-79$ & 244 (37.3) \\
\hline$\geq 80$ & $122(18.6)$ \\
\hline \multicolumn{2}{|l|}{ Sex } \\
\hline Male & 458 (69.9) \\
\hline Female & $197(30.1)$ \\
\hline \multicolumn{2}{|l|}{ Ethnicity } \\
\hline White British & $568(86.7)$ \\
\hline Black/African/Caribbean/black British & 24 (3.7) \\
\hline Asian/Asian British & $43(6.6)$ \\
\hline Other & $20(3.1)$ \\
\hline \multicolumn{2}{|l|}{ Employment status } \\
\hline Paid employment & $134(20.5)$ \\
\hline Retired & 483 (73.7) \\
\hline Housewife/husband & $2(3.1)$ \\
\hline Unemployed/student & $36(5.5)$ \\
\hline \multicolumn{2}{|l|}{ Relationship status } \\
\hline Married/civil partner & $388(59.2)$ \\
\hline Cohabiting & $27(4.1)$ \\
\hline Spouse/partner deceased & $122(18.6)$ \\
\hline Separated & $14(2.1)$ \\
\hline Divorced & 41 (6.3) \\
\hline Single/non-cohabiting partner & $63(9.6)$ \\
\hline \multicolumn{2}{|l|}{ Duration of CHD, years } \\
\hline$<1$ & $29(4.4)$ \\
\hline $1-1.9$ & $46(7.0)$ \\
\hline $2-4.9$ & $124(18.9)$ \\
\hline $5-9.9$ & $171(26.1)$ \\
\hline $10-19.9$ & 185 (28.2) \\
\hline$\geq 80$ & 100 (15.3) \\
\hline
\end{tabular}

${ }^{a}$ Mean (SD). $C H D=$ coronary heart disease. $S D=$ standard deviation.
- anxiety symptoms (HADS-Anxiety);

- depression symptoms (HADS-Depression);

- common mental disorders (CIS-R);

- mental functional capacity (SF-12-Mental); and

- physical functional capacity (SF-12Physical).

\section{PSYCHLOPS qualitative data}

Analysis of the free-text responses followed a process previously devised for analysing qualitative data that were derived from PSYCHLOPS. ${ }^{16}$ The method was based on content analysis, which was used to generate response categories. The categorisation system was developed and any discrepancies in categorisation were resolved. The end product of this analysis was the generation of a number of response categories that encompass the issues described in the free-text responses.

\section{Statistical methods}

The mean score on each psychometric instrument was calculated for each of the response categories identified by PSYCHLOPS and for each of the three free-text questions within PSYCHLOPS. Most attention was paid to each patient's main problem, the first free-text response. Four principal potential confounders were identified:

- age;

- sex;

- time since CHD diagnosis; and

- the Index of Multiple Deprivation (IMD2010), a measure of local deprivation linked to national census area. ${ }^{17}$

with symptomatic CHD. ${ }^{15}$ Comparator instruments consisted of three measures of psychological status:

- Hospital Anxiety and Depression Scale (HADS) questions on anxiety (HADSAnxiety);

- HADS questions on depression (HADSDepression); and

- the Clinical Interview Schedule - Revised (CIS-R), which is a measure of common mental disorders.

Also two measures of functional capacity:

- Short Form-12 questions on mental functional capacity (SF-12-Mental); and

- Short Form-12 questions on physical functional capacity (SF-12-Physical).

The range of comparator instruments provides metrics for the severity of:
Mean scores were then adjusted for the four potential confounders using linear regression. Regression analysis was used to make a more detailed comparison between the response categories and to test the hypothesis that patients with continuing CHD symptoms differ in their psychometric characteristics when compared with those reporting other problems. Psychometric scores for patients reporting CHD symptoms as their main problem were also compared with scores for patients reporting other problem categories. Patients reporting CHD symptoms were used as the comparator group; in order to make this comparison, indicator variables (or dummy variables) were included in the regression model for all other problem categories.

The regression model produced 

Table 2. Patient response categories derived from PSYCHLOPS:
category groups and examples of free-text responses

\begin{tabular}{|c|c|c|}
\hline Problem category group & Response category & Responses \\
\hline \multirow[t]{2}{*}{ Physical } & Physical, cardiac & $\begin{array}{l}\text { 'Palpitations' } \\
\text { 'Pains in the chest' } \\
\text { 'Coronary heart disease' }\end{array}$ \\
\hline & Physical, non-cardiac & $\begin{array}{l}\text { 'Back pain' } \\
\text { 'Prostate problems' } \\
\text { 'Incontinence' }\end{array}$ \\
\hline Psychological & Psychological & $\begin{array}{l}\text { 'Bereavement of a son over a } \\
\text { year ago and trying to move on' } \\
\text { 'Lost my confidence' } \\
\text { 'Can't relax' }\end{array}$ \\
\hline \multirow[t]{6}{*}{ Social } & Relationships/family & $\begin{array}{l}\text { 'Husband is getting older and slower' } \\
\text { 'Loneliness and wanting to go out } \\
\text { more and meet others' } \\
\text { 'Stress in relationship with my wife' }\end{array}$ \\
\hline & Work & $\begin{array}{l}\text { 'Not working' } \\
\text { 'Having to give up my job' } \\
\text { 'Can't do manual work anymore' }\end{array}$ \\
\hline & Money & $\begin{array}{l}\text { 'Paying the mortgage' } \\
\text { 'Income' } \\
\text { 'Money and finances - may have to } \\
\text { go bankrupt' }\end{array}$ \\
\hline & Functional & $\begin{array}{l}\text { 'Bending' } \\
\text { 'Cannot do the things I used to } \\
\text { because of health and that of my } \\
\text { husband' } \\
\text { 'I can't get out to wash my windows' }\end{array}$ \\
\hline & Miscellaneous & $\begin{array}{l}\text { 'Getting the cats in at night' } \\
\text { 'The state of the country' } \\
\text { 'Lack of courtesy and understanding } \\
\text { from society' }\end{array}$ \\
\hline & No problem & $\begin{array}{l}\text { 'I don't have any problems' } \\
\text { No problems' } \\
\text { Nothing' }\end{array}$ \\
\hline
\end{tabular}

estimates of the mean size of the differences in scale scores, adjusted for confounding as described above. All analysis was performed using Stata (version 11.2).

\section{RESULTS}

\section{Sample characteristics}

All 803 participants completed a PSYCHLOPS questionnaire at baseline. However, complete psychometric questionnaire data were only available for $655(81.6 \%)$ of the consented participants; the remaining 148 were either excluded from the study or did not complete the questionnaire. The analysis was confined to the sample of 655 responders with complete data.

The sociodemographic characteristics of the sample are summarised in Table 1. Patients were mainly male $(69.9 \%)$, older (mean age 70.6 years), retired (75.2\%), and predominantly white British (86.7\%). In terms of social deprivation, their mean IMD-2010 score of 20.3 is slightly lower than the London mean of 25.2 and England mean of $21.67 . .^{18}$

\section{Response categories derived from PSYCHLOPS}

Responses to the three free-text questions within PSYCHLOPS were categorised into eight main problem categories:

- physical, cardiac;

- physical, non-cardiac;

- psychological;

- relationships/family;

- work;

- money.

- functional; and

- miscellaneous.

A ninth category of 'no problem' was also used when appropriate. A summary of freetext responses in each category is displayed in Table 2.

Six of the eight categories could be further clustered into three problem category groups:

- physical (physical, cardiac, and physical, non-cardiac);

- psychological (psychological); and

- social Irelationships/family, work, and moneyl.

The functional category consisted of any reported restrictions in physical or psychological capacity at home, outdoors, or at work.

The frequency of responses in each category varied according to the PSYCHLOPS domain question. For the first problem category (P1), the three most frequent classifications were:

- physical, non-cardiac ( $n=152,23.2 \%$ );

- social, relationship/family $(n=119$, $18.2 \%)$; and

- no problem ( $n=119,18.2 \%)$.

Even though all patients were selected from $\mathrm{CHD}$ registers, only a small proportion cited a response in the 'physical, cardiac' category as their main problem $(n=39$, 6.0\%). Full results are displayed in Table 3.

On combining the main-problem (P1) and second-problem (P2) categories, those reporting a physical problem accounted for 

Table 3. Patient response categories derived from PSYCHLOPS:
frequency of main problem reported by each patient $(n=655)$

\begin{tabular}{lc} 
Response category & Response frequen \\
\hline Physical, cardiac & $39(6.0)$ \\
Physical, non-cardiac & $152(23.2)$ \\
Psychological & $45(6.9)$ \\
Soical, relationships/family & $119(18.2)$ \\
Social, work & $20(3.1)$ \\
Social, money & $49(7.5)$ \\
Functional & $64(9.8)$ \\
Miscellaneous & $48(7.3)$ \\
No problem & $119(18.2)$
\end{tabular}

PSYCHLOPS = Psychological Outcome Profiles. and F1 and, partly, because a further 267 patients (40.8\% of the study sample) did not record a second-problem response. A high proportion of 'functional' responses to the F1 question, as would be expected, resulted in 'functional' being the second-most cited response category in the pooled results.

\section{Confounding by sex, age, ethnicity, and} duration of CHD

Adjustment for confounding produced different weightings for each psychometric instrument (data not shown). In general, males scored lower (less severity) on the psychological instruments but had higher physical functional scores, while older people reported lower anxiety and depression scores. Mental functional capacity improved with age, but physical functional capacity diminished with age.

Patients of Asian and black ethnicity had similar scores on all instruments exceptions were depression, for which patients of black ethnicity reported higher HADS-Depression scores, and common mental disorders, for which patients of Asian ethnicity reported higher CIS-R scores.

Social deprivation was associated with somewhat higher anxiety and depression scores, statistically significantly higher scores for common mental disorders, but no difference in functional capacity.

The duration of CHD had no independent effect on the scores of either the psychological or functional instruments. Re-analysing data to explore for possible score differences in the first year after diagnosis with $\mathrm{CHD}$ produced no statistically significant differences

\section{Psychometric characteristics of response categories}

Psychometric scores for each of the five instruments included in our study, stratified according to PSYCHLOPS response category and adjusted for confounding are displayed in Table 4 and illustrated in Figures 1-5.

\section{Patients reporting their main problem as 'physical, cardiac'}

Patients reporting 'physical, cardiac' problems had statistically significantly higher anxiety and depression levels and levels of common mental disorders than those with 'physical, non-cardiac' problems. Functional capability, on the other hand, was similar to those with 'physical, non-cardiac' problems (Table 4). The highest scores (worst affected) for anxiety, depression, and common mental 


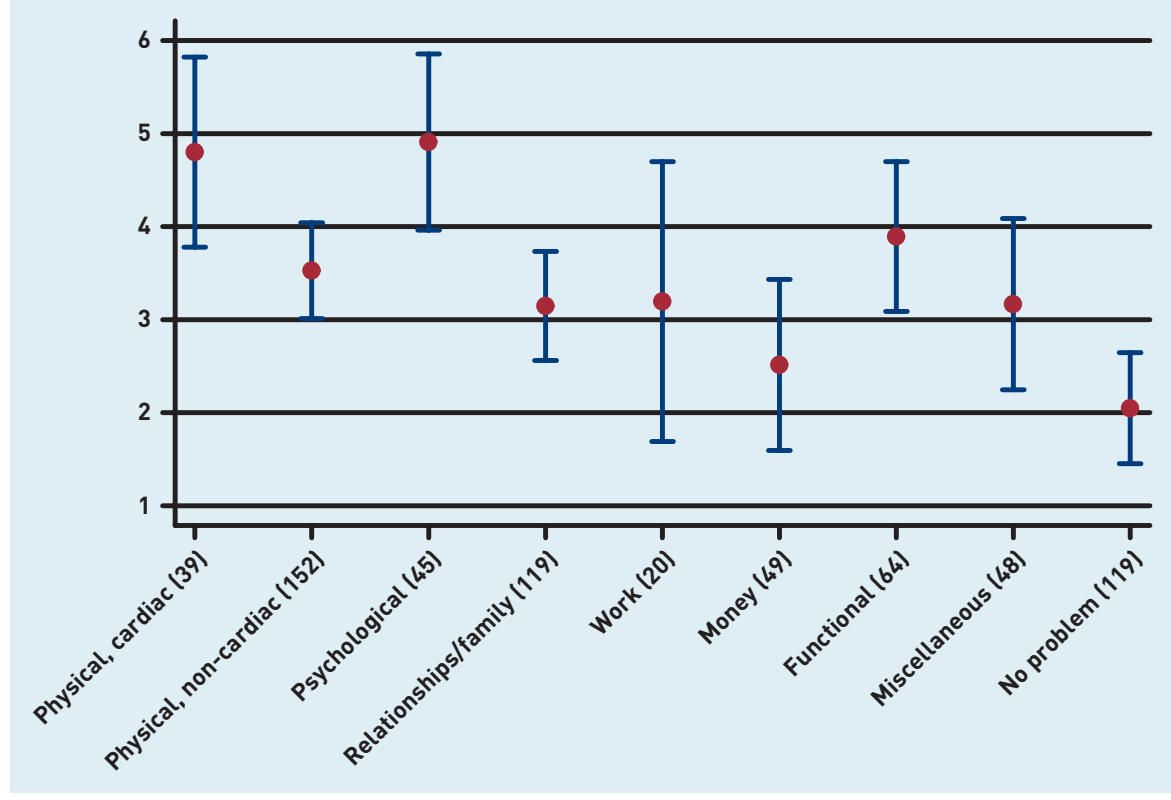

Figure 2. Adjusted mean HADS-Depression scores, according to PSYCHLOPS response categories.

Figure 3. Adjusted mean CIS-R scores, according to PSYCHLOPS response categories.

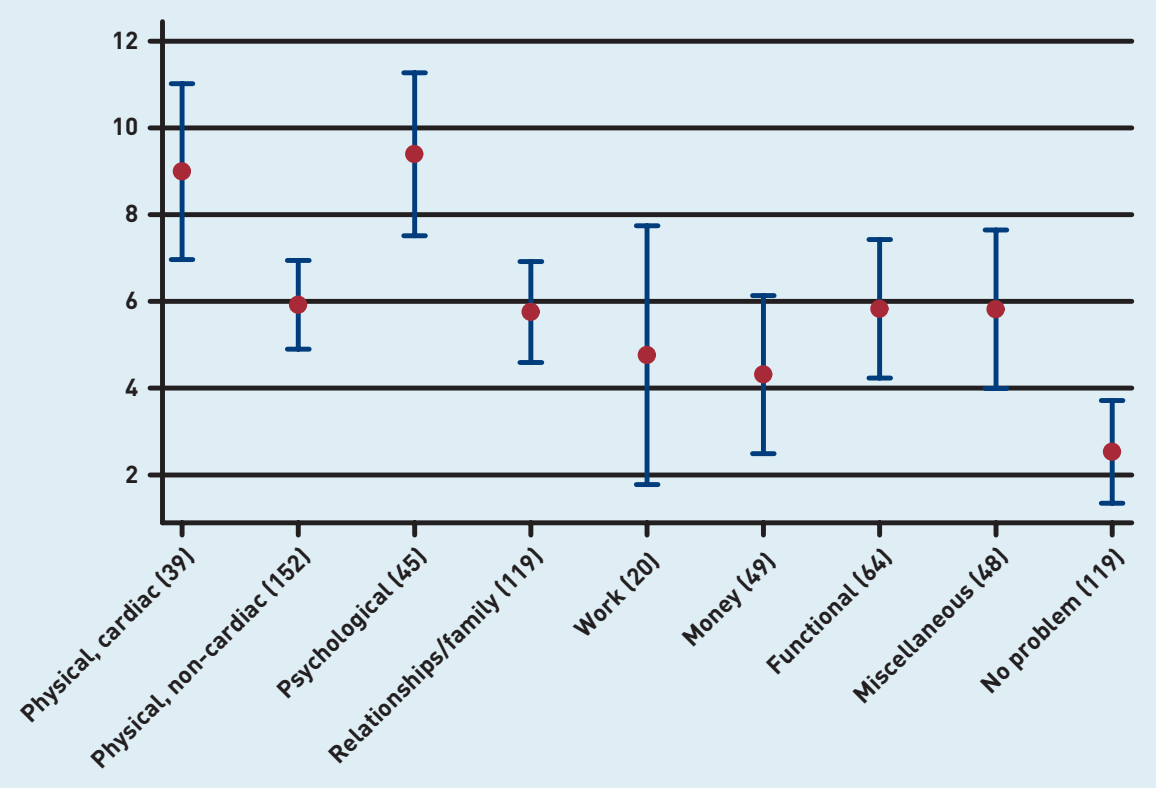

psychometric profile to those with other physical, psychological, or social problems. The results of the regression analysis are summarised in Table 5.

\section{Patients reporting their main problem as \\ 'functional'}

Although the F1 question on PSYCHLOPS elicits functional information, $9.8 \%$ of patients also included functional content in their response to the $\mathrm{P} 1$ question. Those with a 'function' response category had good mental functioning but poor physical functioning on the two functional scales (Figures 1-5)

\section{DISCUSSION}

\section{Summary}

PSYCHLOPS has been used to determine the principal self-perceived problems of a cohort of patients with $\mathrm{CHD}$ in primary care who are on the CHD register. This instrument enabled the definition of three broad domains of response categories: physical (cardiac and non-cardiac); psychological, and social lwork, money, relationships/family). A fourth category of 'functional' defined those reporting functional impairment. Free-text responses were diverse.

Almost $30 \%$ of patients reported that their main problem was physical and a further 30\% that their main problem was social. Nearly $20 \%$ reported a 'no problem' response.

Continuing cardiac symptoms were relatively uncommon as the main problem of concern in our cohort of patients with CHD, but were associated with high levels of psychological distress. Social problems were relatively common, wide ranging, and just as troubling in psychological terms as non-cardiac physical health problems.

The two 'physical' categories had varying psychometric properties. 'Physical, cardiac' was associated with higher anxiety and depression scores than physical, noncardiac', although functional capacity (both physical and mental functioning) was similar. Indeed, those in the physical, cardiac' category had anxietyand depression scores almost equalling the scores of the most distressed group, namely those in the 'psychological' category.

The three 'social' categories lwork, money, relationships/familyl behaved similarly on the three psychological measures and had 'intermediate' scores that were comparable to those of patients in the 'physical, non-cardiac, 'functional,' and 'miscellaneous' categories; however, these were lower (indicating less severity) than 


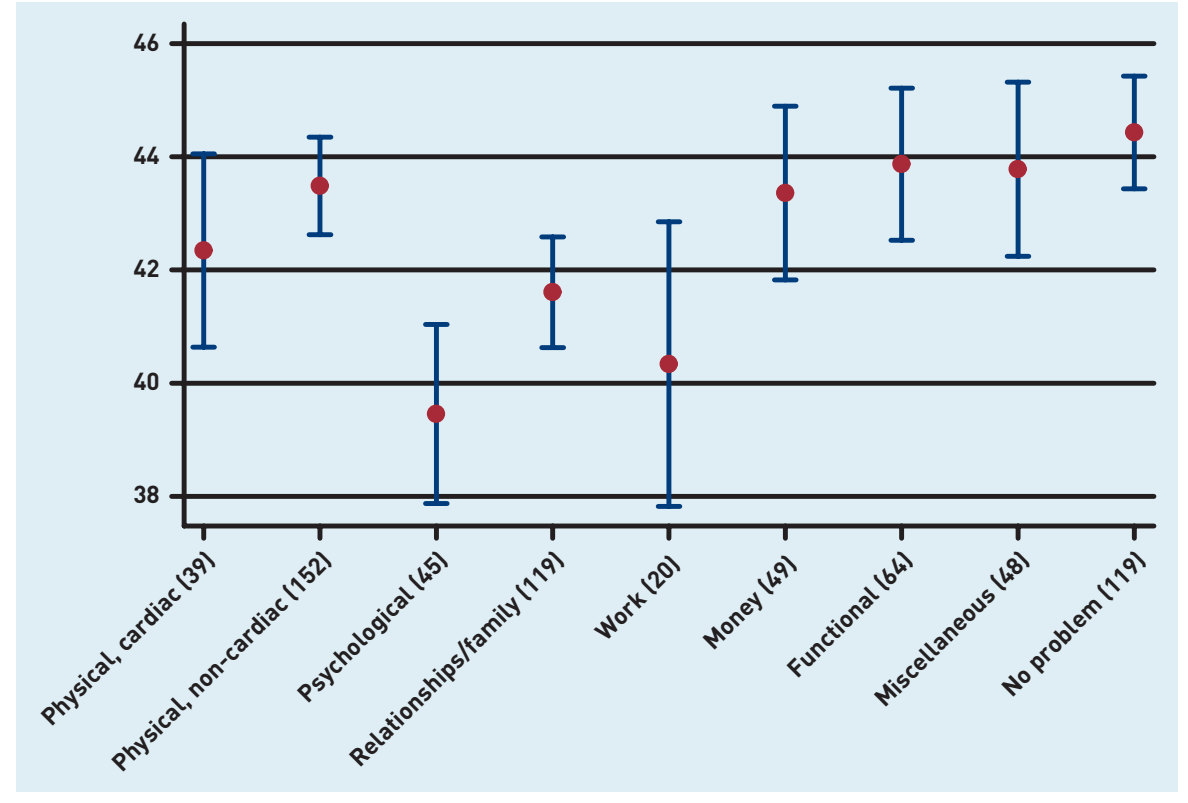

Figure 4. Adjusted mean SF-12-Mental scores, according to PSYCHLOPS response categories.

Figure 5. Adjusted mean SF-12-Physical scores, according to PSYCHLOPS response categories.

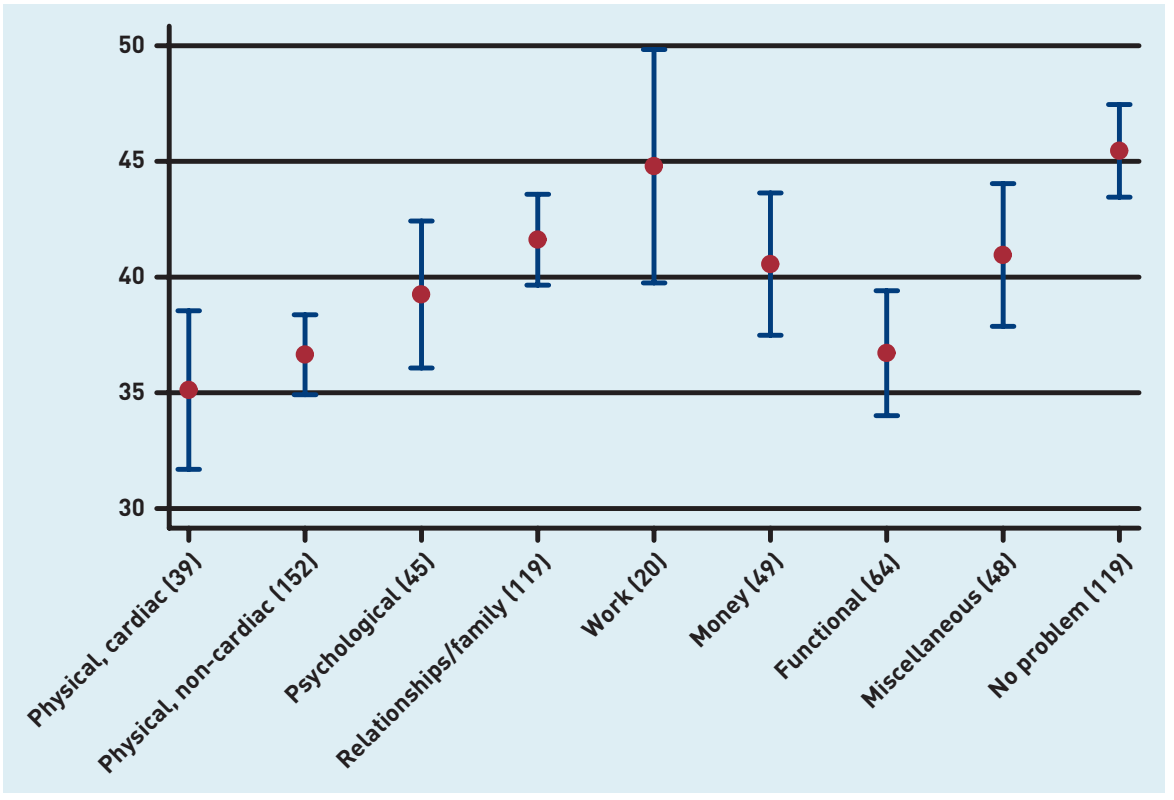

two most frequently reported problem types. By deriving categories of responses contained in PSYCHLOPS, it was possible to identify those with the highest levels of psychological distress.

PSYCHLOPS elicits specific information about a patient's perceived problem but does not specify the severity of the problem over its full duration. It does not, therefore, distinguish between persistent severe or short-term severe problems, with both types of problem achieving similar scores. Similarly, the responses elicited by PSYCHLOPS are personal and it could not be determined how generalisable these findings are to other cohorts of patients with $\mathrm{CHD}$; this limitation also applies to other qualitative studies however.

The order effect was not tested in the study. PSYCHLOPS was completed at the end of a large battery of questionnaires and some patients may have given the no problem' response due to question fatigue.

This study was an opt-in study with just one-fifth of potentially eligible patients with CHD agreeing to, and successfully completing, a researcher-led interview and a series of questionnaires. Comparison of the sample with data for England indicates generalisability: the study sample were predominantly male $(70 \%)$ and data for England indicates that $62 \%$ of $\mathrm{CHD}$ patients are male; the mean age of participants was 71 years, while national data indicates that $93 \%$ of patients with CHD are aged $>55$ years and $79 \%>65$ years. ${ }^{19}$ Nevertheless, without more details of patients who did not opt in to the study, it is not possible to verify the generalisability of the physical, psychological, and social problems described in the analysis.

\section{Comparison with existing literature}

In general, validated PGIs are used to guide treatment decisions or to contribute to service evaluation. ${ }^{20}$ The findings of this study have demonstrated that one PGI, PSYCHLOPS, may have a role in identifying patient sub-types within a larger cohort, based on a classification of self-reported problems. Analysis of patient responses within PSYCHLOPS enabled the identification of various physical, psychological, and social sub-types of patients with CHD, and has provided an insight into which sub-types experience the greatest psychological distress or functional impairment. PSYCHLOPS has also demonstrated that a sizeable minority of patients with $\mathrm{CHD}$ consider that they have no problems and have a correspondingly good psychological status and functional capacity. 

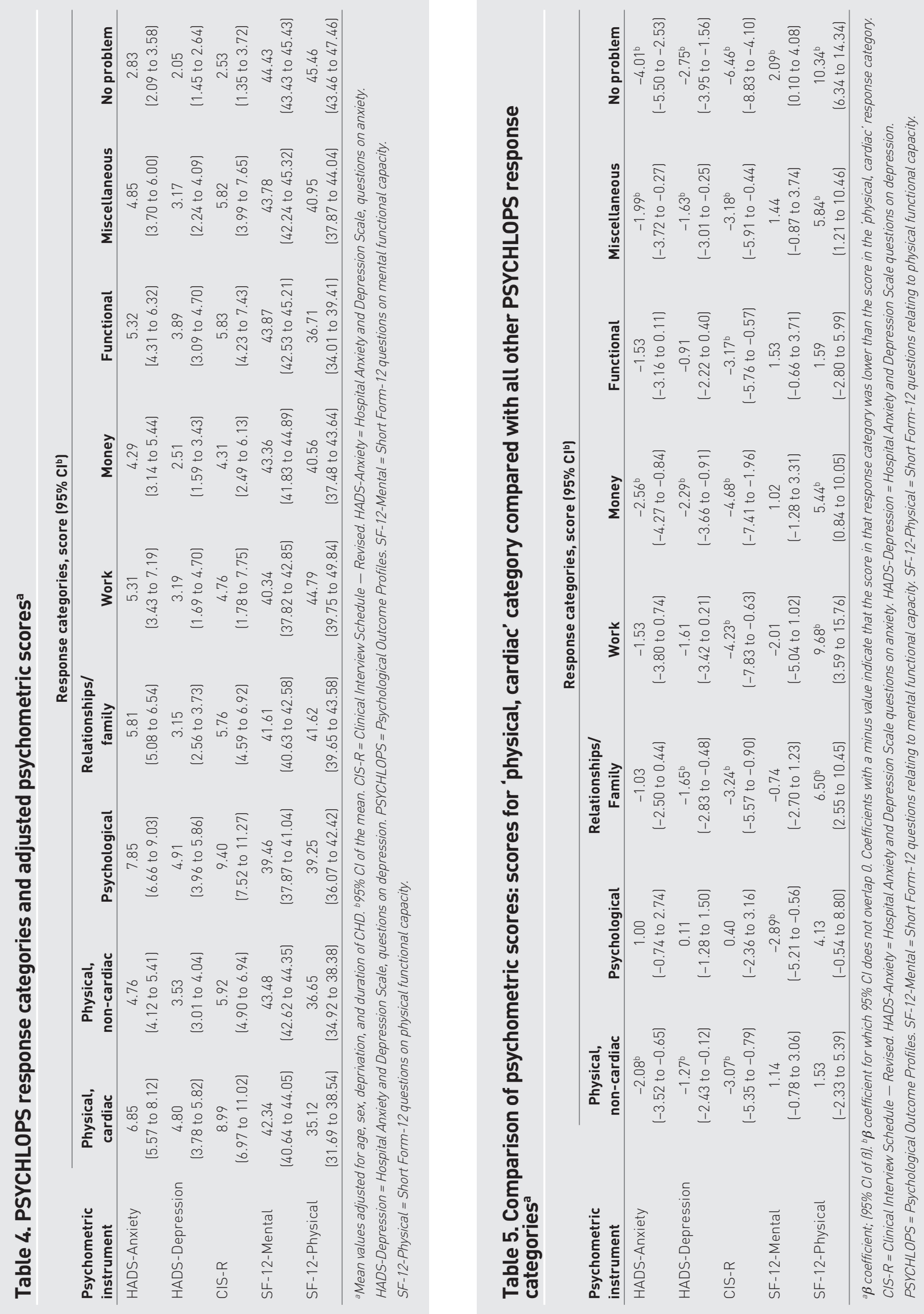
Nevertheless, the finding that $18.2 \%$ of patients reported 'no problem' is in keeping with reports that a proportion of patients report positive effects rather than problems following an MI. ${ }^{21,22}$

These findings bear many similarities to those of other large surveys of patients with $\mathrm{CHD}$ using standardised instruments. One survey of post-Ml patients in the US administered four social scales and two psychological scales to 196 patients and found high levels of depression, especially among younger and poorer patients. The four social scales had differing associations with depression severity; lack of social support was most strongly associated with depression. ${ }^{23}$ In a Canadian survey, one psychological measure and one social measure were administered to 887 patients, following their $\mathrm{Ml}$; these patients were found to have high levels of depression and social isolation, and higher levels of social support were associated with improvements in depression symptoms. ${ }^{24}$

However, each of these larger studies utilised standardised tools rather than eliciting the patient's own perspective. Findings were, therefore, constrained by the breadth of the commonly used measures that may fail to capture issues of concern to patients with a cardiac history. 25,26 There may also be discrepancies between patients' measures of disease severity and narrative accounts. ${ }^{27}$ In contrast, the starting point for this survey was the patient's own description of their main problem, as contained in the free-text box of PSYCHLOPS. Although other studies have demonstrated the importance of social issues in patients with $\mathrm{CHD}$, this has largely been determined by administering measures of social support. ${ }^{23,24}$ This study has demonstrated that other social issues, such as work and money, were also of importance.

\section{Implications for practice}

These findings reveal the high proportion of patients with CHD who report social problems. The diversity of social problems would not have been identified through standardised social instruments that focus on social support. Both researchers and clinicians need to be aware of the diversity of social problems and that for a third of patients with CHD, issues such as work, money, and social support were considered to be more important than physical or psychological symptoms.

Psychological distress, when it was reported, was more severe. This may reflect patients' reluctance to discuss psychological issues unless they are particularly troublesome. Physical symptoms were not associated with undue psychological distress; the exception was the minority of patients with cardiac physical symptoms, who reported significantly greater distress. Given the relationship between cardiac prognosis and psychological distress, patients with continuing cardiac symptoms may benefit most from psychological interventions. ${ }^{2}$

Further research is needed into the subtypes of patients with CHD. For example patients treated with drugs alone, coronary artery stents, or cardiac bypass surgery are likely to report different physical, psychological, and social outcomes. ${ }^{28}$

\section{Funding}

This study was funded by a Programme Grant for Applied Research (reference number: RP-PG-0606-1048) from the National Institute for Health Research.

\section{Ethical approval}

Ethical approval was granted by Bexley and Greenwich Research Ethics Committee (reference number: 07/H0809/38).

\section{Provenance}

Freely submitted; externally peer reviewed.

\section{Competing interests}

The authors have declared no competing interests.

\section{Discuss this article}

Contribute and read comments about this article: www.bjgp.org/letters 


\section{REFERENCES}

1. Davidson KW, Kupfer DJ, Bigger JT, et al. Assessment and treatment of depression in patients with cardiovascular disease: National Heart, Lung, and Blood Institute Working Group Report. Psychosom Med 2006; 68(5): 645-650.

2. Brotman DJ, Golden SH, Wittstein IS. The cardiovascular toll of stress. Lancet 2007; 370(9592): 1089-1100.

3. Grace SL, Abbey SE, Pinto R, et al. Longitudinal course of depressive symptomatology after a cardiac event: effects of gender and cardiac rehabilitation. Psychosom Med 2005; 67(1): 52-58.

4. Frasure-Smith $\mathrm{N}$, Lespérance F. Recent evidence linking coronary heart disease and depression. Can J Psychiatry 2006; 51(12): 730-737.

5. Katon W, Von Korff M, Lin E, et al. Improving primary care treatment of depression among patients with diabetes mellitus: the design of the pathways study. Gen Hosp Psych 2003; 25(3): 158-168.

6. Lane D, Carroll D, Ring $C$, et al. Mortality and quality of life 12 months after myocardial infarction: effects of depression and anxiety. Psychosom Med 2001; 63(2): 221-230.

7. Ruo B, Rumsfeld JS, Hlatky MA, et al. Depressive symptoms and health-related quality of life: the heart and Soul Study. JAMA 2003; 290(2): 215-221.

8. Roebuck A, Furze G, Thompson DR. Health-related quality of life after myocardial infarction: an interview study. J Adv Nurs 2001; 34(6): 787-794

9. Kristofferzon M, Löfmark R, Carlsson M. Coping, social support and quality of life over time after myocardial infarction. J Adv Nurs 2005; 52(2): 113-124.

10. Simmonds RL, Tylee A, Walters P, Rose D. Patients perceptions of depression and coronary heart disease: a qualitative UPBEAT-UK study. BMC Fam Pract 2013; 14: 38. DOI: 10.1186/1471-2296-14-38

11. Provisional monthly Patient Reported Outcome Measures (PROMS) in England April 2011 to March 2012, July 2013 release. Health and Social Care Information Centre, Leeds, 2013. http://uww.hscic.gov.uk/catalogue/PUB11069 laccessed 6 May 2014]

12. Richardson A, Cotton R. No health without mental health: developing an outcomes based approach. Mental Health Network NHS Confederation, London, Dec 2011. http://www.nhsconfed.org/Documents/MHN\%20Mental\%20 Health\%200utcomes\%20Report.pdf laccessed 6 May 2014).

13. Ashworth M, Robinson S, Godfrey E, et al. Measuring mental health outcomes in primary care: the psychometric properties of a new patient-generated outcome measure, 'PSYCHLOPS' ('Psychological Outcome Profiles'). Primary Care Mental Health 2005; 3(4): 261-270.

14. Ashworth M, Evans $C$, Clement S. Measuring psychological outcomes after cognitive behaviour therapy in primary care: a comparison between a new patient-generated measure, 'PSYCHLOPS' (Psychological Outcome Profiles) and 'HADS' (Hospital Anxiety Depression Scale). J Ment Health 2009: 18(2): 169-177.
15. Tylee A, Ashworth M, Barley E, et al. Up-Beat UK: a programme of research into the relationship between coronary heart disease and depression in primary care patients. BMC Fam Pract 2011; 12: 38. DOI: 10.1186/1471-2296-12-38.

16. Ashworth M, Robinson S, Evans $C$, et al. What does an idiographic measure (PSYCHLOPS) tell us about the spectrum of psychological issues and scores on a nomothetic measure (CORE-OM)? Primary Care and Comm Psych 2007; 12(1): $7-16$

17. McLennan D, Barnes H, Noble M, et al. The English Indices of Deprivation 2010. Communities and Local Government, London, 2011. https://mww.gov.uk/ government/uploads/system/uploads/attachment data/file/6320/1870718.pdf laccessed 6 May 2014).

18. Public Health England. Summary IMD-2010 scores for non-LSOA geographies. http://www.apho.org.uk/resource/item.aspx?RID=111280 (accessed 6 May 2014).

19. Townsend N, Wickramasinghe $K$, Bhatnagar $P$, et al. Coronary heart disease statistics. A compendium of health statistics. 2012 edn. London: British Heart Foundation, 2012.

20. Patel KK, Veenstra DL, Patrick DL. A review of selected patient-generated outcome measures and their application in clinical trials. Value Health 2003, 6(5): 595-603

21. Petrie KJ, Buick DL, Weinman J, Booth RJ. Positive effects of illness reported by myocardial infarction and breast cancer patients. J Psychosom Res 1999; 47(6): 537-543.

22. Hassani P, Afrasiabifar A, Khoshknab MF, Yaghmaei F. Perceived positive effects of illness following acute myocardial infarction. Int J Nursing and Midwifery 2009; 1(1): $1-5$.

23. Barefoot JC, Burg MM, Carney RM, et al. Aspects of social support associated with depression at hospitalization and follow-up assessment among cardiac patients. J Cardiopulm Rehabil 2003; 23(6): 404-412.

24. Frasure-Smith N, Lespérance F, Gravel G, et al. Social support, depression and mortality during the first year after myocardial infarction. Circulation 2000; 101(16): 1919-1924.

25. Dunderdale K, Thompson DR, Miles JN, et al. Quality-of-life measurement in chronic heart failure: do we take account of the patient perspective? Eur J Heart Fail 2005; 7(4): 572-582

26. Paul S, Sneed N. Patient perceptions of quality of life and treatment in an outpatient congestive heart failure clinic. Congest Heart Fail 2002; 8(2): 74-79.

27. Campbell R, Quilty B, Dieppe P. Discrepancies between patients' assessments of outcome: qualitative study nested within a randomised controlled trial. BMJ 2003; 326(7383): 252-253.

28. Abdallah MS, Wang K, Magnuson EA, et al, for the FREEDOM Trial Investigators. Quality of life after PCI vs CABG among patients with diabetes and multivessel coronary artery disease. A randomized clinical trial. JAMA 2013; 310(15): 1581 1590. 